\title{
Ophthalmia neonatorum in the 1980s: incidence, aetiology and treatment
}

\author{
J. M. PIERCE, ' M. E. WARD, ${ }^{1}$ AND D. V. SEAL ${ }^{2}$
}

From the 'Department of Microbiology, Southampton University Medical School, Southampton General Hospital, Tremona Road, Southampton, and the ${ }^{2}$ Public Health Laboratory, Southampton General Hospital, Southampton

SUMMARY In a survey of 450 consecutive births in Southampton a $12 \%$ incidence has been found of ophthalmia neonatorum. Bacterial pathogens were isolated from only one-third of the cases, while nonpathogens were isolated from as many cases as controls. There was an incidence of chlamydial infection of $3 \cdot 7$ per 1000 live births, while Neisseria gonorrhoeae could not be found. Chloramphenicol is recommended for topical antibacterial treatment, but chlamydial infection will not respond; it must be considered in 'resistant' cases, when both the neonate and the parents will need treatment with erythromycin or tetracycline.

Conjunctivitis is frequently seen in newborn babies, yet its aetiology often remains obscure. In Britain Staphylococcus aureus, Streptococcus pneumoniae and Haemophilus sp. are established pathogens, as was Neisseria gonorrhoeae. However, Pseudomonas aeruginosa, ${ }^{1}$ Klebsiella spp., Escherichia coli, Str. viridans and Staph. albus, ${ }^{2}$ herpes simplex virus types I and II, ${ }^{3}$ adenovirus type $8^{4}$ and Mycoplasma spp. ${ }^{56}$ have also been isolated from cases of ophthalmia neonatorum (ON). Chlamydia trachomatis is also being recognised as of increasing importance as a cause of $\mathrm{ON}^{7}$ Chlamydial $\mathrm{ON}$ differs from other infections by being contracted in the intrapartum period but developing after the baby has left hospital. It does not respond to the usually applied topical antibiotics and is known to progress to further ocular and extraocular complications. ${ }^{8-11}$

This study set out to establish prospectively the incidence and type of $\mathrm{ON}$ in Southampton, including its natural history and most appropriate treatment. Currently used antibiotic therapy was determined by a survey of general practitioners (GPs), to whom many cases present because of our existing policy of early discharge of the mother from hospital.

\section{Materials and methods}

The study population consisted of consecutive births

Correspondence to Dr D. V. Seal, Department of Microbiology, Northwick Park Hospital, Watford Road. Harrow, Middlesex HAl 3UJ. in the Maternity Unit of Southampton General Hospital between 1 January and 31 March 1981. All mothers were resident in the Southampton area. Each infant was observed for a period of 2 weeks for the development of $\mathrm{ON}$. This was diagnosed by the presence of an acute, overt ocular discharge and conjunctival hyperaemia. Neonates were excluded if the discharge did not resolve but became continuous owing to anatomical abnormalities such as nasolacrimal duct obstruction. The observation was continued outside the hospital by the GP, and each case was visited by one of us (J.M.P.).

Cultures were collected from the inferior palpebral conjunctival surface on 2 sterile cotton-wool swabs. One swab was placed in sucrose phosphate transport medium and the material inoculated within one hour on to diethylaminoethyl (DEAE)-dextran-treated HeLa 229 cells for the isolation of $C$. trachomatis by the method previously described. ${ }^{12}$ Material from the second swab was immediately cultured on to chocolate agar for bacteria at $37^{\circ} \mathrm{C}$ in $5 \% \mathrm{CO}_{2}$ in air for 48 hours, before being transferred to blood agar to observe for haemolysis by streptococci. Bacteria were identified with standard laboratory techniques. Antibiotic sensitivity testing was performed by the disc method. ${ }^{13}$ Anaerobic cultures were not carried out, as the number of samples which could be taken was limited by the quantity of the discharge; moreover anaerobes are considered a rare cause of ON. ${ }^{5}$ Control cultures were collected from neonates with normal eyes individually matched for age at onset of symptoms, type 
of delivery, location of delivery, and location of rooming-in (post-natal ward).

One hundred and five general practitioners in Southampton were surveyed for their management of ON and asked to list their antibiotic regimen for arbitrary therapy. General practice was considered the most likely discipline to which cases of chlamydial ON would initially present.

\section{Results}

In the period of the study there were 450 deliveries; 54 of the babies developed $\mathrm{ON}$, giving a $12 \%$ incidence in unselected births. The organisms isolated from 42 of these cases in which swabs were collected are given in Table 1 and are grouped into recognised pathogens and nonpathogens. The results from the matched control neonates are also included. By the $\chi^{2}$ test Staphylococcus aureus was not found significantly more often among cases than controls $(p>0 \cdot 10)$ but Streptococcus viridans was $(p<0 \cdot 001)$. $N$. gonorrhoeae was never isolated despite the use of a sensitive culture technique for it. Recognised pathogens were found more often among cases than controls ( $p$ $<0.001$ ). There was no significant difference between the numbers of nonpathogens in cases and controls, but there was a higher rate of sterile cultures from the control population. C. trachomatis was isolated on only one occasion (listed in Table 1). It was decided therefore to extend the study to another 100 neonates to look only for this organism; one further neonate was identified with it-inclusion conjunctivitis of the newborn (ICN).

Antibiotic sensitivity tests showed that chlortetra-

Table 1 Organisms isolated from 42 cases and matched controls

\begin{tabular}{lcc}
\hline Bacteria & $\begin{array}{c}\text { Ophthalmia } \\
\text { neonatorum }\end{array}$ & $\begin{array}{c}\text { Control } \\
\text { neonates }\end{array}$ \\
\hline PATHOGENS & & \\
Staph. aureus & 2 & 2 \\
Staph. aureus and Chlamydia trachomatis & 1 & 0 \\
Staph. aureus and Streptococcus viridans & 1 & 2 \\
Str. viridans & 6 & 0 \\
Str. milleri & 1 & 0 \\
H. influenzae & 2 & 0 \\
Haemophilus sp. & 1 & 0 \\
Escherichia coli & 1 & 4 \\
Subtotal & 15 & \\
NonPaTHogens & & 16 \\
Mixed Staph. epidermidis, diphtheroids, & & 4 \\
and micrococci & 11 & 0 \\
Pure micrococci & 2 & 20 \\
Pure diphtheroids & 1 & 18 \\
Subtotal & 14 & 42 \\
No growth & 13 & \\
Total & 42 & \\
\hline
\end{tabular}

Table 2 Types of antibiotics prescribed by 59 general practitioners

\begin{tabular}{ll}
\hline Type of antibiotic & \% of GPs prescribing each antibiotic \\
\hline Chloramphenicol & 66 \\
Sulphacetamide & 12 \\
Gentamicin & 9 \\
Neomycin & 6 \\
Chlortetracycline & 4 \\
Framycetin & 2 \\
Polymyxin + bacitracin & 1 \\
\hline
\end{tabular}

cycline was effective against all the bacteria associated with $\mathrm{ON}$ and chlamydia of ICN. Chloramphenicol was similarly found to be effective against all the bacterial cases but not against $C$. trachomatis. Streptococci were resistant to gentamicin and framycetin (neomycin). Sulphonamide was not generally effective.

Seventy-nine $(75 \%)$ of general practitioners answered the questionnaire about prescribing habits for ON. Of these, $59(75 \%)$ prescribed various antibiotics (Table 2$)$, while $15(19 \%)$ only occasionally did so. Chloramphenicol was the most popular and used by $66 \%$ of the GPs, while chlortetracycline was used by only $4 \%$. Many replies indicated that failure to respond to topical antimicrobial therapy combined with washing the affected eye rarely occurred. The number of topical antibiotic applications and the duration of therapy was found to be very varied; the commonest regimen was 4-hourly. Although chlamydial infection of the cervix is sexually transmissible, only $18 \%$ of the GPs would have referred or treated both parents, so as to eradicate carriage of $C$. trachomatis and prevent future offspring from developing ICN.

\section{Discussion}

From 450 unselected deliveries in Southampton $12 \%$ of infants developed ON. In 1977 among newborn babies in Harrow the incidence was a comparable $8.4 \%,{ }^{5}$ showing that in both areas $\mathrm{ON}$ is a common condition. However, in America, where Credé's prophylaxis is routinely used, Armstrong et al. ${ }^{14}$ found the incidence to be $1.6 \%$, but this has to be contrasted with toxic effects that can occur with it.

The unpaired Student's $t$ test was used to compare those neonates who subsequently developed $\mathrm{ON}$ with a random control population born in the same maternity unit and over the same period. It was found that health in the immediate postpartum period, as judged by the Apgar score at one minute, did not affect the chance of developing ON: neither did the length of the second stage of labour, nor mechanical intervention at birth. But the neonate's conjunctiva is prone to infection, not only because there are low levels of antibacterial tear proteins, namely, 
lysozyme ${ }^{15}$ and $\operatorname{IgA}$, but also because the tear flow and film are only beginning to develop.

Staphylococcus aureus was not found more often among cases than among controls. This is probably because there was no obvious cross-infection within the unit and no outbreaks occurred due to it. Other workers have found it to be important. ${ }^{1416}$ Streptococcus viridans was isolated significantly more often from cases (17\% of the total) than controls. Previous studies by Prentice et al. ${ }^{5}$ and $\mathrm{McGill}^{2}$ have shown Str. viridans to be isolated in $16 \%$ and $18 \%$ of cases of ON respectively and in the latter showed a positive correlation with the presence of pus cells. 'Nonpathogenic' skin flora was found alike in ON and controls and can probably be ignored as a cause of $\mathrm{ON}$.

There were two cases of $C$. trachomatis ICN among 550 consecutive deliveries, giving an incidence of 3.7 per 1000 live births. This compares with American studies which put the incidence between 1.4 and 4.4 per 1000 live births. ${ }^{14}{ }^{17-19}$ However, British studies have found $C$. trachomatis to be less prevalent than in Southampton. Prentice in Harrow in $1977^{5}$ did not find any cases of ICN among 103 cases of $O N$, whereas McGill $^{2}$ in Ayrshire found 2 cases of ICN among 213 cases. However, in a selected study of severe purulent ocular discharge in neonates in eastern Glasgow in $197938 \%$ of 199 specimens were found to grow $C$. trachomatis. ${ }^{20}$ In Liverpool ${ }^{21} C$. trachomatis was recovered from $36 \%$ of 81 cases of ON preselected for their resistance to conventional treatment.

Our failure to isolate organisms from $30 \%$ of cases of ON could be partly explained by the fact that we did not culture for Mycoplasma, for which an infection rate of $3 \%$ has been found, ${ }^{6}$ or viruses. A more likely explanation is that initial inadequate tear flow rather than an infectious aetiology is involved. Support for this latter hypothesis is presented by a number of observations. Firstly, the natural history is for a tendency towards spontaneous resolution within 48 to 72 hours even in those cases with a frank purulent discharge, provided the affected eyes are washed with sterile saline. Secondly, in our survey $19 \%$ of GPs prescribed antibiotics only occasionally yet at the same time claimed as much success in treating the condition as those who prescribed antibiotics in all cases. Thirdly, $12 \%$ of GPs prescribed sulphacetamide, yet it was found that organisms from cases of $\mathrm{ON}$ are not generally sensitive to it.

Chlortetracycline is the only effective antibiotic against most bacteria of $\mathrm{ON}$ and chlamydia of ICN. However, its indiscriminate use would lead to masking of those neonates with ICN and hence the failure to identify asymptomatic parenteral carriage. Neomycin and chloramphenicol are both active against most of the bacteria causing $O N$, with chloramphenicol being effective against streptococci.
Neomycin has the advantage that it does not mask chlamydial $\mathrm{ICN}^{22}$ but also has the serious disadvantage of being ineffective against streptococci and is associated with contact sensitisation.

The rarity with which $C$. trachomatis is isolated (in Southampton 3\% of all cases of $\mathrm{ON}$ ) and the laborious and costly isolation procedure for it suggest that there should be a high index of clinical suspicion, such as severe chloramphenicol-resistant conjunctivitis, before conjunctival swabs are collected for chlamydial culture in those areas fortunate enough to have a chlamydial culture service. Ideally, to increase the likelihood of $C$. trachomatis isolation, swabs should be collected into special transport medium $^{12}$ after 2 days' treatment with neomycin. ${ }^{22}$ The treatment of choice for ICN is topical chlortetracycline for several days and oral erythromycin 30 $\mathrm{mg} / \mathrm{kg} / \mathrm{day}$ for 3 weeks. ${ }^{23}$ Oral chemotherapy is also necessary to reduce pharyngeal carriage. ${ }^{24}$ Both parents of neonates with proved ICN must also receive effective antichlamydial therapy $-250 \mathrm{mg}$ oral tetracycline or erythromycin 4 times a day for 3 weeks, with erythromycin being the drug of choice if breast feeding.

\section{References}

1 Cole GF. Davies DP. Austin DJ. Pseudomonas ophthalmia neonatorum: cause of blindness. Br Med J 1980; ii: 440-1.

2 McGill RET. Neonatal eye infections. Communicable Diseases (Scotland). Weekly Report 1979; 22: ix.

3 Csonka GW. Coofalik ED. Chlamydial, gonococcal and herpes virus infection in neonates. Postgrad Med J 1977; 53: 592-4.

4 Dawson CR, Jawetz E. Hanna L. Winn W. Thompson JG. A family outbreak of adenovirus 8 infection (epidemic keratoconjunctivitis) Am J Hvg 1960; 72: 279-83.

5 Prentice MJ. Hutchinson GR. Taylor-Robinson D. A microbiological study of neonatal conjunctivae and conjunctivitis. $\mathrm{Br} J$ Ophthalmol 1977; 61: 607-10.

6 Jones DM. Tobin B. Neonatal eye infections due to $M$. hominis. Br Med J 1968; iii: 467-8.

7 Chandler JW. Alexander ER. Pfeiffer JA. Wang SP. Holmes KK. English M. Ophthalmia neonatorum associated with maternal chlamydial infections. Trans Am Acad Ophthalmol Otolaryngol 1977; 83: 302-8.

8 Rees F. Tait IA. Hobson D. Byng RE, Johnson FWA. Neonatal conjunctivitis caused by $N$. gonorrhoeae and $C$. trachomatis. Br J Vener Dis 1977; 53: 173-9.

9 Schacter J, Lum L. Gooding CA, Ostler B. Pneumonitis following inclusion blennorrhoea. J Paediatr 1975; 87: 779-80.

10 Beem MO. Saxon EM. Respiratory tract colonisation and distinctive pneumonia syndrome in infants infected with $C$. trachomatis N Engl J Med 1977; 296: 306-10.

11 Hobson D. Rees E. Maternal genital infection as a cause of neonatal conjunctivitis. Postgrad Med J 1977; 53: 595-7.

12 Salari HS. Ward ME. Early detection of Chlamydia trachomatis using fluorescent DNA binding eyes. J Clin Pathol 1979; 32: $1155-62$

13 Stokes EJ, Waterworth PM. Antibiotic sensitivity testing. ACP Broadsheet 1972; 55.

14 Armstrong JH. Zacarius F. Rein MF. Ophthalmia neonatorum. A chart review. Pediatrics 1976; 57: 884-92.

15 Etches PC. Leahy F. Harris D. Baird JD. Lysozyme in the tears of newborn babies. Arch Dis Child 1979; 54: 218-21. 
16 Kaivonen M. Prophylaxis of ophthalmia neonatorum. Acta Ophthalmol (Kbh) 1965; suppl 79: 1-70.

17 Allen JH. Inclusion blennorrhoea. Part I. Manifestations in the newborn. Am J Ophthalmol 1944; 27: 833-46.

18 Schachter J. Chlamydial infections. N Engl J Med 1978; 298: 540-9.

19 Thygeson P. Stone W. Epidemiology of inclusion conjunctivitis. Arch Ophthalmol 1942; 27: 91-122.

20 Sommerville RG, Lunum CB, Wolfsberger J. Neonatal chlamydial eye infection in the eastern district of Glasgow, 1979. Communicable Diseases (Scotland). Weekly Report 1980; 8: vii.
21 Rees E. Tait IA, Hobson D, Johnson FWA. Perinatal chlamydial infection. In: Hobson D. Holmes KK. eds. Nongonococcal Urethritis and Related Infection. Washington: American Society of Microbiology. 1977.

22 Bason TWT. Davidson DC. Neonatal chlamydial conjunctivitis. Br Med J 1979; ii: 961.

23 Ridgeway GL. Oriel JD. Treatment of neonatal inclusion blennorrhoea. N Engl J Med 1977; 297: 512.

24 Rees E. Tait IA. Hobson D. Karaviannis P. Lee N. Persistence of chlamydial infection after treatment for neonatal conjunctivitis. Arch Dis Child 1981: 56: 193-8. 